Article

\title{
Performance Simulation and Assessment of an Appropriate Wastewater Treatment Technology in a Densely Populated Growing City in a Developing Country: A Case Study in Vientiane, Laos
}

\author{
Chanthephar Khattiyavong ${ }^{1,2}$ and Han Soo Lee ${ }^{2, *(D)}$ \\ 1 Department of Water Supply, Ministry of Public Works and Transport of Lao PDR. Lanxang Avenue, \\ Vientiane 4107, Laos; Chanthephar@gmail.com \\ 2 Graduate School for International Development and Cooperation, Hiroshima University, 1-5-1 Kagamiyama, \\ Higashi-Hiroshima 739-8529, Hiroshima, Japan \\ * Correspondence: leehs@hiroshima-u.ac.jp; Tel.: +81-82-424-4405
}

Received: 31 March 2019; Accepted: 11 May 2019; Published: 15 May 2019

check for updates

\begin{abstract}
The fast-growing population in Vientiane, the capital of Laos, has resulted in increasing domestic wastewater generation, which directly impacts the urban water environment due to the lack of a suitable wastewater treatment system. This study aims to assess six wastewater treatment alternatives based on two technologies-trickling filter and activated sludge-used for on-site, decentralized, and centralized wastewater treatment systems to support decision-making for selecting the most suitable and practical alternative for wastewater treatment in Vientiane. To determine the most appropriate treatment system, the wastewater treatment process simulation with BioWin and the technique for order preference by similarity to ideal solution (TOPSIS) method are applied to assess the removal efficiencies for biochemical oxygen demand (BOD), chemical oxygen demand (COD), and total suspended solids (TSS), as well as to rank the six wastewater treatment technologies based on the following four environmental criteria: (1) land requirement, (2) electricity use, (3) sludge production, and (4) $\mathrm{CO}_{2}$ emissions. The BioWin results illustrate that the capacity of each alternative is similar in terms of domestic wastewater treatment efficiency, while differing in terms of environmental impacts. In addition, the alternative ranking shows that a centralized wastewater treatment system with a trickling-filter process is more suitable than on-site and decentralized wastewater treatment systems based on their environmental impacts. This finding provides evidence for decision-makers to select a suitable alternative for wastewater treatment in order to promote access to safe sanitation and sustainable urban wastewater management in Vientiane, Laos.
\end{abstract}

Keywords: wastewater treatment; BioWin; TOPSIS; environmental impact; Vientiane

\section{Introduction}

Currently, municipal sanitation and wastewater management has become a challenging issue for sustainable environmental development in developing countries. In 2015, only $39 \%$ of the worldwide population had access to safe and managed sanitation services [1]. While social and economic development are growing in Asian countries, they are also facing serious water pollution problems [2]. The growing population in urban areas has resulted in increasing drinking-water demand and supply. This increase influences municipal wastewater generation, and urban water pollutants have direct impacts on human health and the environmental, economic, and social qualities of life.

Particularly, Vientiane, the capital of Laos, faces an issue of municipal wastewater management due to lack of suitable sanitation and wastewater treatment systems, including a sewerage network 
system. Most of the wastewater from domestic, commercial, and industrial areas in Vientiane is directly discharged into receiving waters, such as drainage canals, streams, marshes, lakes, and finally the Mekong River. Domestic wastewater is treated by using only on-site wastewater disposal and basic treatment facilities, such as pour-flush and septic tanks [3]. However, these treatment facilities are often of poor design, construction, maintenance, and operation. Additionally, most of the grey water generated from kitchen, bathroom, and washing is still not treated before discharging into the environment. The critical issue appears in that the wastewater quality from average households has a biochemical oxygen demand (BOD) effluent concentration of from 100 to $110 \mathrm{mg} / \mathrm{L}$ for septic tanks, and the BOD concentration of grey water discharged without treatment ranges from 200 to $230 \mathrm{mg} / \mathrm{L}$ [4]. Those concentrations are higher than the national standard of discharged BOD concentrations from households (BOD < $30 \mathrm{mg} / \mathrm{L}$ ) based on the National Environmental Standard in Laos, 2017 [5].

To enhance the efficiency of the environmental protection of water and human health qualities in Vientiane, it is necessary to upgrade and improve the accessibility of safely managed sanitation services and suitable wastewater treatment systems and to promote the international targets of sustainable development goals (SDGs) of Article 6 [6] and the international strategy for water, sanitation, and hygiene for 2016-2030 [7]. Therefore, to find appropriate technology potentials for wastewater treatment and sustainable environmental development, socio-economic and environmental conditions have to be considered for each specific region.

In general, several technologies for municipal sanitation and wastewater treatment in developing countries have been developed and adopted from those in developed countries according to local conditions, climate-geography aspect, and financial mechanism and capability [8]. In particular, trickling filter and aeration processes can be applied in developing countries. The trickling filter process is a biofilm system that is widely recognized and used around the world. The biofilm referred to is a biological growth developed on the surface of filter media, known as a bio-filter, in biological wastewater processes. The aeration process is an activated sludge operation based on pumping air into a tank to promote microbial growth in the wastewater [8]. The trickling filter and aeration processes can be operated for on-site, decentralized, and centralized wastewater treatment systems [8,9].

Selection of appropriate wastewater treatment technologies from conventional treatment options to advanced technologies which enable sustainable development presents a challenge to decision makers. To determine the most appropriate technology for the particular wastewater treatment objective at a particular site, many factors (criteria) are involved in the decision-making process which pose the multi-criteria decision-making (MCDM) problem [10]. Numerous methods are now available for decision making, and more than 50 MCDM techniques are documented in the literature, ranging from the highly sophisticated to simple rating systems [11,12]. Extensive description on the history and types of MCDM can be found in [10]. In the selection of wastewater treatment alternatives, MCDM has been applied in many cases [13-16], but Kalbar et al. [10] stated that a scenario-based MCDM method considering the indicators derived from life cycle assessment (LCA) and life cycle costing (LCC) of wastewater treatment technologies is more logical in technology selection.

Regarding wastewater management and development, it is also very challenging to select appropriate treatment technology considering the regional constraints. The technique for order preference by similarity to ideal solution (TOPSIS), proposed by Hwang and Yoon [11], is one of the MCDM approaches and can be applied to the scenario-based selection of appropriate technology [17]. The concept of TOPSIS is to define an index called similarity (or relative closeness) to the positive ideal solution by combining the proximity to the positive ideal solution and the remoteness from the negative ideal solution. This method can easily be implemented computationally and can be made available as a decision-support tool for the end users [10].

Therefore, the aims of this study are to investigate the wastewater treatment efficiency potentials of several technologies used for on-site, decentralized, and centralized systems and to find an appropriate wastewater technology based on their environmental impacts, namely, (1) land requirement, 
(2) electricity use, (3) sludge production, and (4) $\mathrm{CO}_{2}$ emission. In this study, only domestic wastewater and its treatment management in Vientiane are considered.

In the following, the study area and datasets used in the analysis are described in Section 2. In Section 3, the methodology for wastewater treatment process simulation and appropriate wastewater treatment technology selection based on the four criteria are described. The results of the analysis and discussion are presented in Section 4, followed by the conclusions in Section 5.

\section{Study Area and Data}

\subsection{Study Area}

Vientiane, the capital of Lao People's Democratic Republic (PDR), is a main center of administrative, economic, social, and commercial activities in the country. It covers an area of $3920 \mathrm{~km}^{2}$ with 9 districts and has a total population of approximately 820,900 people with a population density of 209 people per square kilometer in 2015, as shown in Table S1 in the Supplementary Material S1 [18]. The four densely populated districts located in the core urban area of Vientiane were selected for the study area covering approximately $345 \mathrm{~km}^{2}$ or $8.85 \%$ of total area, as shown in Figure 1 and Table 1 . The domestic wastewater in Vientiane is almost all discharged from households and buildings in the urban area [19]. Therefore, the four districts with a high population density, Chanthabuly, Sikhottabong, Xaysetha, and Sisatanak, as shown in Table 1, were selected for the study area with a high priority in solving the wastewater pollutant issue in Vientiane.

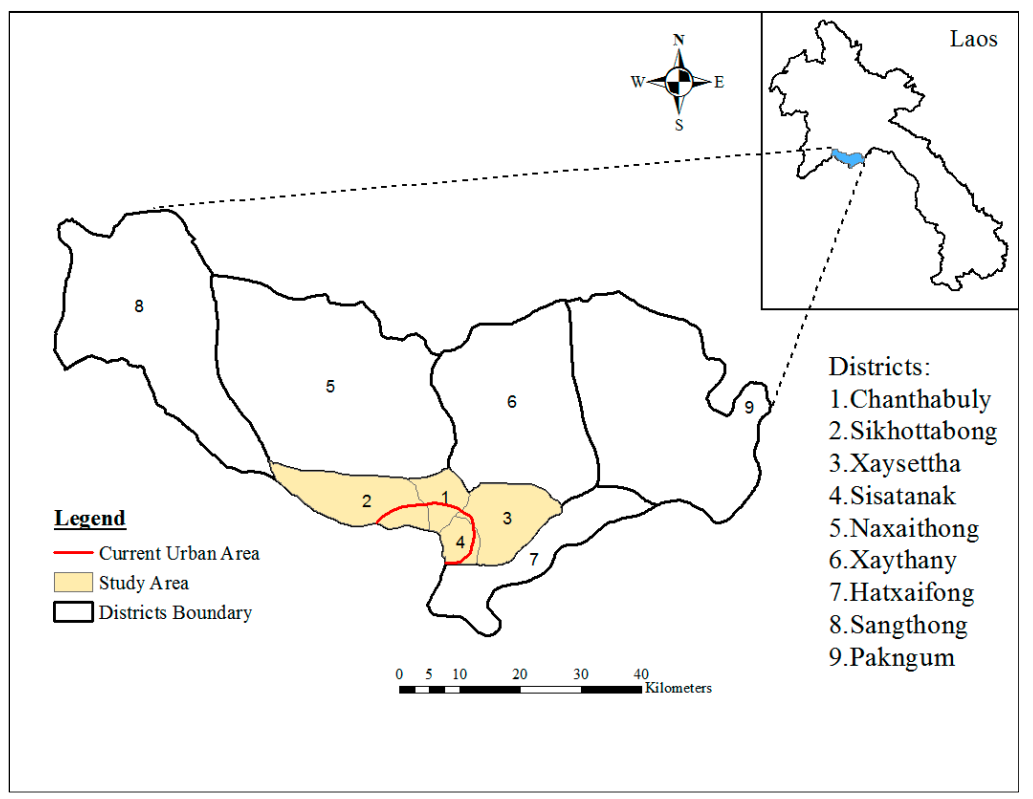

Figure 1. The map of Vientiane, Laos, with the study area and district information.

Table 1. Population in the study area districts of Vientiane.

\begin{tabular}{|c|c|c|c|c|c|c|c|}
\hline \multirow{2}{*}{ No. } & \multirow{2}{*}{ Districts } & \multirow{2}{*}{$\begin{array}{l}\text { Area } \\
\left(\mathrm{km}^{2}\right)\end{array}$} & \multicolumn{3}{|c|}{ Population (People) } & \multirow{2}{*}{$\begin{array}{c}\text { Population Density } \\
\left(\text { People/ } / \mathbf{k m}^{2}\right)\end{array}$} & \multirow{2}{*}{ Remark } \\
\hline & & & 1995 & 2005 & 2015 & & \\
\hline 1 & Chanthabuly & 29 & 58,855 & 68,858 & 69,200 & 2386 & Selected study area \\
\hline 2 & Sikhottabong & 140 & 74,251 & 99,908 & 121,000 & 864 & Selected study area \\
\hline 3 & Xaysetha & 147 & 75,255 & 97,514 & 116,900 & 795 & Selected study area \\
\hline \multirow[t]{2}{*}{4} & Sisatanak & 31 & 58,178 & 68,686 & 65,700 & 2119 & Selected study area \\
\hline & Total & 347 & 266,539 & 334,966 & 372,800 & 209 & - \\
\hline
\end{tabular}




\subsection{Data}

The data used for designing and modelling of a wastewater treatment system were the population in the study area, the raw wastewater parameters in the influent, and the daily water and wastewater generation.

\subsubsection{Wastewater Parameters from Sample}

The raw wastewater parameters were obtained by sampling and analyzing the influent of a decentralized anaerobic wastewater treatment plant (WWTP) that is the only one Community-Based Sanitation (CBS) model from a pilot project in Vientiane. The CBS model, constructed in 2009, is located at Thongkhankham Village, Chanthabuly District. It collects both grey and black waters from 22 households, and the treatment capacity is approximately $11.2 \mathrm{~m}^{3}$ per day [19].

The samples were taken from a pre-chamber before treatment to investigate the influent parameters of wastewater such as BOD, chemical oxygen demand (COD), and total suspended solids (TSS) concentrations from the households, as shown in Figure 2. The influent samples were then analyzed at the laboratory of the Natural Resource and Environment Research Institute of Laos. The analytical results of the influent and effluent samples are presented in Table S2 in the Supplementary Material S1.

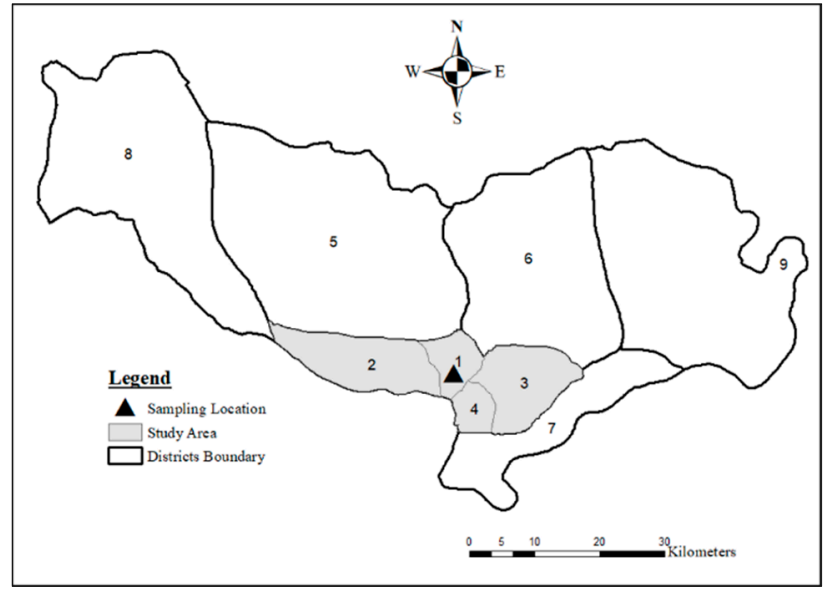

(a)

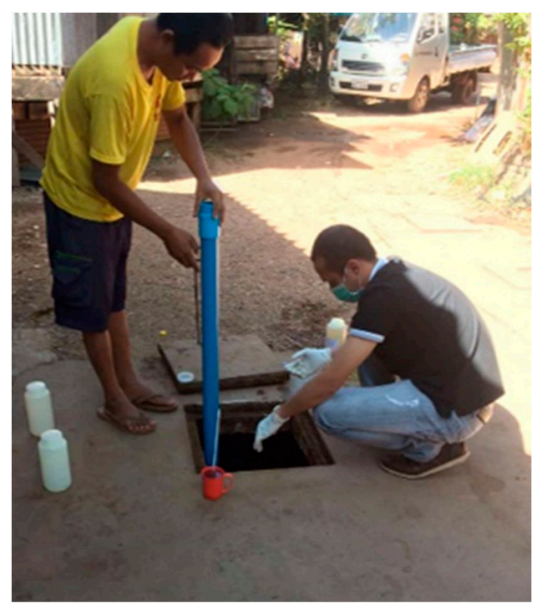

(b)

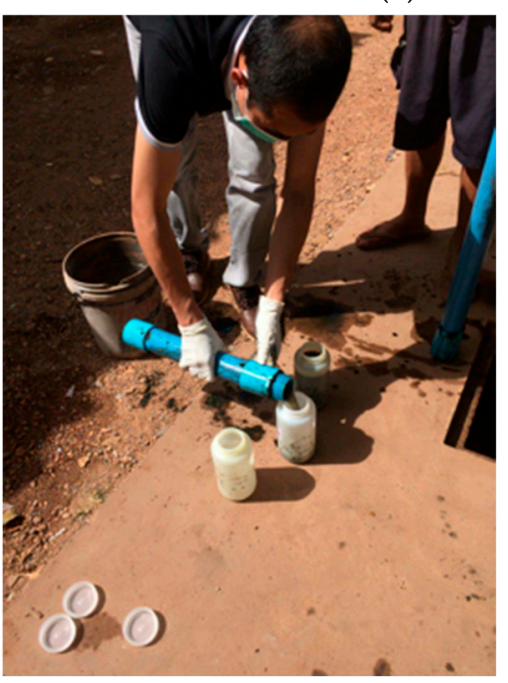

(c)

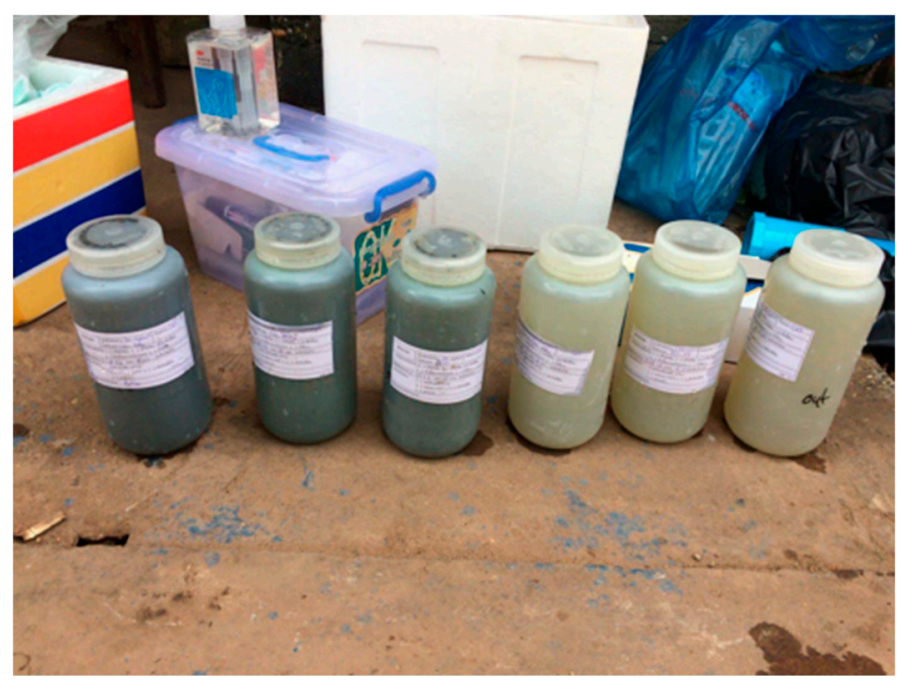

(d)

Figure 2. (a) Sampling location of a decentralized wastewater treatment plant (WWTP) in Vientiane, (b) and (c) sampling photos, and (d) the influent and effluent samples. 


\subsubsection{Population and Wastewater Generation}

The population and its growth in the urban area, including the study area, were obtained from the population and housing census in 2015 [18] as shown in Table 1. In addition, water use information and the database for estimating wastewater flow were obtained from the water supply management and technical guidelines of the Ministry of Public Works and Transport, Laos [20] as depicted in Table S3 in the Supplementary Material S1. Water use in Vientiane ranges from 200 to $250 \mathrm{~L} /$ cap/day in municipalities. Additionally, according to the preliminary feasibility study of wastewater management for Vientiane [4], water use appeared as approximately $245 \mathrm{~L} /$ cap/day. Therefore, this research utilizes a water use rate of $245 \mathrm{~L} /$ cap/day.

\section{Methodology}

An assessment of the efficiencies of wastewater treatment systems for the purpose of selecting an appropriate technology should be associated with several conditions, such as environmental, economic, and social impact factors [21]. In this research, four factors were considered for selecting an appropriate wastewater treatment technology: land requirement, energy use, sludge production, and $\mathrm{CO}_{2}$ emission. These factors were investigated for on-site, decentralized, and centralized treatment systems in terms of the treatment efficiencies in wastewater effluent qualities that satisfy the constraints of the water pollution control standards of Laos in 2017. The constraints of three wastewater effluent parameters in controlling the discharge of wastewater from households are BOD $<30 \mathrm{mg} / \mathrm{L}, \mathrm{COD}<125 \mathrm{mg} / \mathrm{L}$, and TSS $<40 \mathrm{mg} / \mathrm{L}$ [5], considered to be the main indicators of treatment efficiencies. Figure 3 exhibits the analysis flowchart of this study.

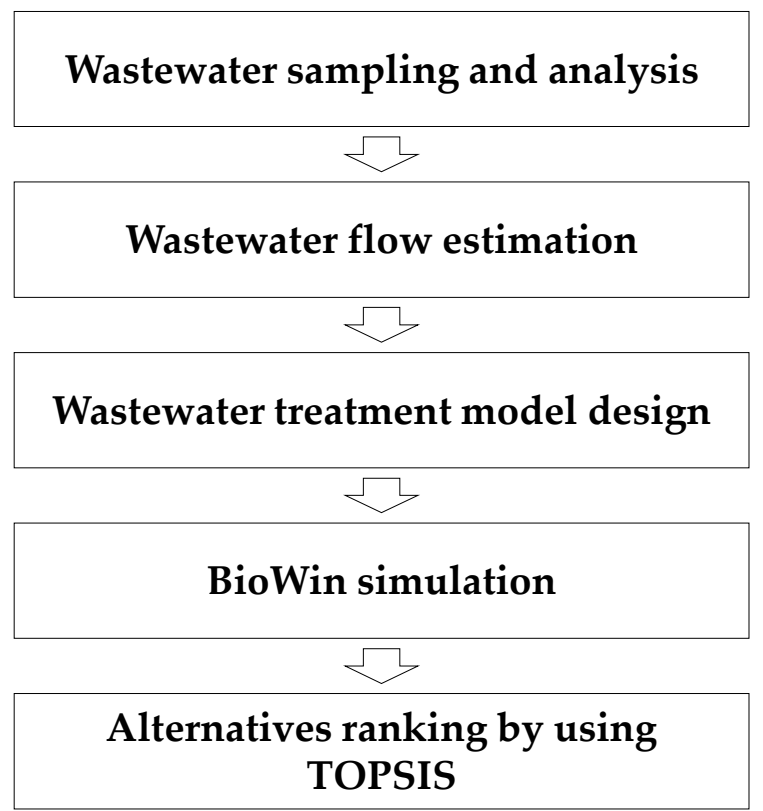

Figure 3. Analysis flowchart for the optimized design of a wastewater treatment system in Vientiane, Laos. TOPSIS: technique for order preference by similarity to ideal solution.

\subsection{Population Projection}

In this study, the population growth in 2035 was predicted to take into account the strategy of wastewater management in Vientiane for 2030 as planned in 2017. The population prediction for 2035 was calculated using the arithmetic increment method (Equation (1)) with the statistics of altering populations in Vientiane for 1995, 2005, and 2015, as shown in Table 1, as follows:

$$
P_{t}=P_{0}+k_{a} t
$$


where $P_{t}$ is the population at a future time, $P_{0}$ is the present population, $k_{a}$ is the arithmetical growth rate constant, and $\mathrm{t}$ is time (y). The result of the population projection in 2035 is approximately 479,061 people, as shown in Table S4 in the Supplementary Material S1; therefore, this study assumes approximately 480,000 people in the four study districts.

\subsection{Wastewater Estimation}

In general, the wastewater ratio is assumed to be $80 \%$ of the generated water use discharged as wastewater according to wastewater engineering [22] and the preliminary feasibility report of wastewater management in Vientiane [4]. Therefore, the domestic wastewater flow was calculated using Equation (2) as follows:

$$
\text { Wastewater flow }=\text { Population }(\text { cap }) \times \text { Water use }(\mathrm{L} / \mathrm{cap} / \mathrm{d}) \times 80 \% \text {. }
$$

For defining the capacity of WWTPs, three plant types were designed: (1) an on-site treatment plant for one household, (2) a decentralized treatment plant for 50 households, and (3) a centralized treatment plant for half of the total households in the study area. The future population in 2035 is estimated to be 480,000 people, and the average size of a household was approximately 4.6 people per household in 2015 [18]. Therefore, in this research, a household size of 5 people was defined for calculating the wastewater flow for all plants. Table 2 shows the required number of WWTPs and their design capacity based on the population projection and designed plant types.

Table 2. The capacity and the required number of WWTPs.

\begin{tabular}{|c|c|c|c|c|c|}
\hline \multirow[b]{2}{*}{ No. } & \multirow[b]{2}{*}{ WWTPs } & \multirow[b]{2}{*}{$\begin{array}{l}\text { Based on Design } \\
\left(\mathrm{HH}^{1} / \text { plant }\right)\end{array}$} & \multirow[b]{2}{*}{$\begin{array}{c}\text { Required } \\
\text { Number (plant) }\end{array}$} & \multicolumn{2}{|c|}{ Wastewater Flow } \\
\hline & & & & $\begin{array}{l}\text { Calculation } \\
\left(\mathrm{m}^{3} / \mathrm{d} / \text { plant }\right)\end{array}$ & $\begin{array}{c}\text { Design Capacity } \\
\left(\mathrm{m}^{3} / \mathrm{d} / \text { plant }\right)\end{array}$ \\
\hline 1 & $\begin{array}{l}\text { On-site systems } \\
\text { (On-site) }\end{array}$ & 1 & 96,000 & 0.98 & 1 \\
\hline 2 & $\begin{array}{c}\text { Decentralized } \\
\text { systems (DEWATS) }\end{array}$ & 50 & 1920 & 49.00 & 50 \\
\hline 3 & $\begin{array}{c}\text { Centralized } \\
\text { systems (CEWATS) }\end{array}$ & 48,000 & 2 & $47,040.00$ & 48,000 \\
\hline
\end{tabular}

\subsection{Wastewater Treatment Model}

The wastewater treatment systems considered for on-site, decentralized, and centralized systems consist of six models based on combining and adapting basic and advanced technologies that are popular and available in developed and developing countries. In particular, two technologies, trickling filters and aeration processes/activated sludge, among many others were selected and utilized for the analysis of each system as illustrated in Figure 4 because they are easy on operation and maintenance, highly efficient, and appropriate technology with local material. The trickling filter technology is actually implemented at the pilot on-site system at Thongkhankham Village, Chanthabuly District in Vientiane [19].

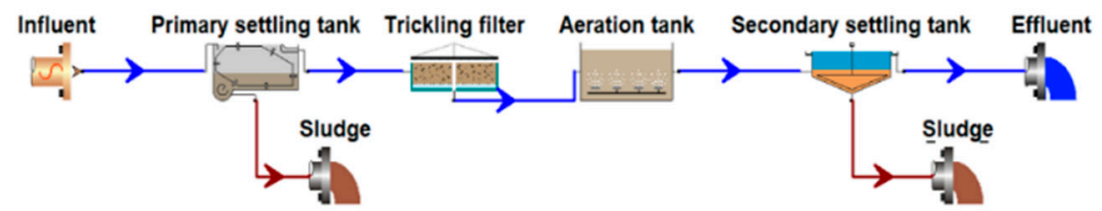

(a) Trickling filter and aeration processes (On-site I).

Figure 4. Cont. 


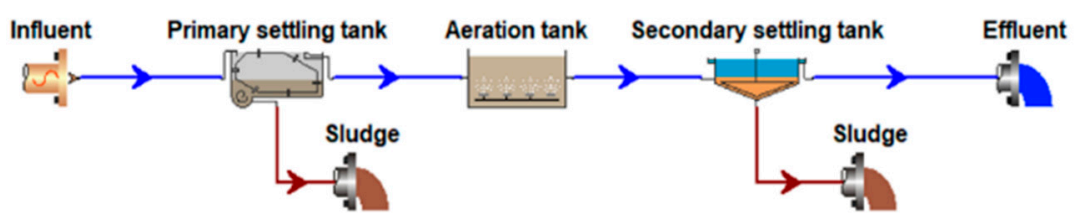

(b) Aeration process (On-site II).

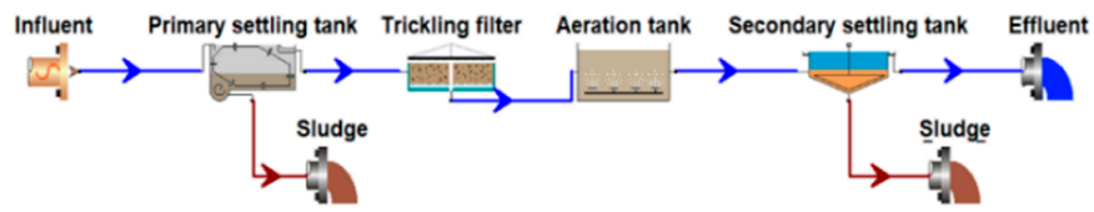

(c) Trickling filter and aeration processes (DEWATS I).

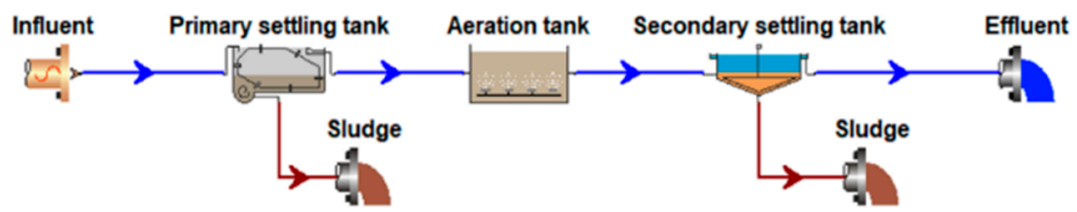

(d) Aeration process (DEWATS II).

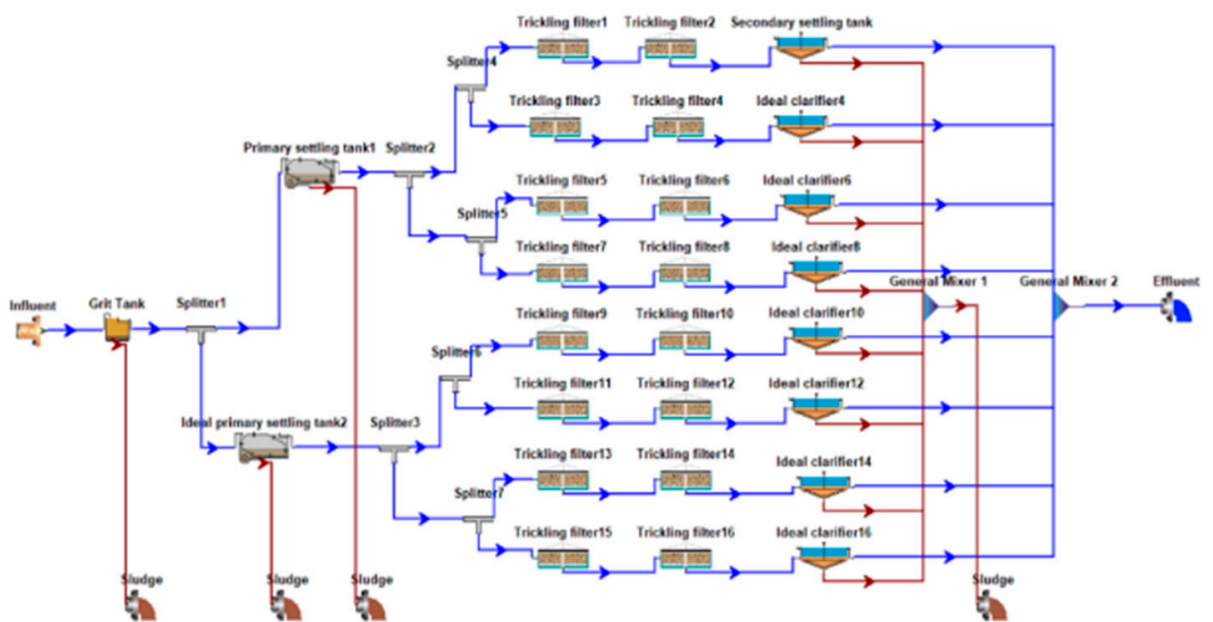

(e) Trickling filter process (CEWATS I).

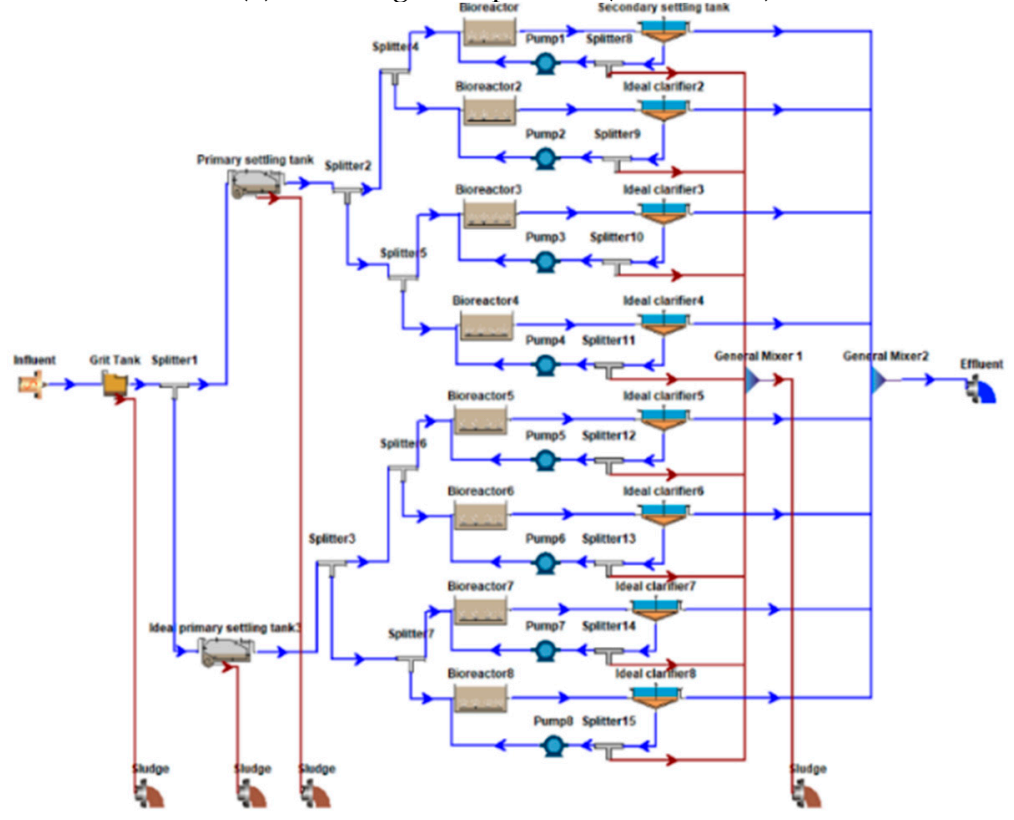

(f) Aeration process (CEWATS II).

Figure 4. Six wastewater treatment models considered in the BioWin simulations. 
When designing the six models, we have thoroughly checked and referred to the following guidelines: A Guideline to the Development of On-Site Sanitation [23], On-site Wastewater Systems: Design and Management Manual [24], Design Manual: On-Site Wastewater Treatment and Disposal Systems [9], On-Site Wastewater Treatment Systems Manual [25], Water and Wastewater Calculations Manual [26], and Wastewater Engineering [22,27,28]. All of these are main guidelines and manuals for designing sanitation and wastewater treatment systems for engineers in this research field.

\subsection{BioWin Simulation}

BioWin (version 5.2) developed by EnviroSim Associates is well-established computer software for wastewater treatment process simulation. BioWin is used to design, upgrade, and optimize all types of WWTPs with physical, biological, and chemical process models [29]. In this study, to produce a reliable result rather than testing various tools, BioWin was applied to create six wastewater treatment models, and each process of each model was operated one by one in the BioWin simulation. The results of the BioWin simulations then were observed to check their efficiencies to determine whether the resulting effluent parameters satisfy the constraints of the Laos standards.

First, in the BioWin simulation, the BOD influent object was used to impose the input data for the raw influent with constant inflow based on the sampling and analytical results for BOD, COD, and TSS concentrations and wastewater engineering references except for nitrate, alkalinity, calcium, and magnesium values from BioWin defaults because there were no data available.

For the primary clarifier process, an ideal primary settling tank object was used in the rectangle model by setting underflow and settling efficiency according to the BioWin manual and calculations. The trickling filter object was used to simulate a trickling filter by gravity flow over a rock-media filter. For the aeration process, the bioreactor element was utilized to simulate the tank size and air flow demand for the design results.

For the secondary clarifier process, an ideal clarifier element was utilized to model the settling of the remaining particulate material in the wastewater by using only physical characteristics.

Finally, after defining each element and its parameter in each wastewater treatment model, the BioWin simulations for each model were continuously conducted for five days, and the simulation results, such as the effluent concentrations of BOD, COD, and TSS, were evaluated to determine whether or not they satisfy the water pollution control standards of Laos. If the effluent concentrations did not satisfy the standards, then the tunable parameters at each step of each model were adjusted and the simulation was repeated until the effluent met the standards.

\subsection{TOPSIS Analysis}

TOPSIS was used to rank the alternatives to select based on the preference information. The concept of TOPSIS is exhibited in Figure S1a in the Supplementary Material S1, indicating that the chosen alternative should be closest to the positive ideal solution and farthest from the negative ideal solution [11]. In this study, the TOPSIS method was applied to the ranking of the six alternatives, as shown in Figure 4, based on four criteria to select the most appropriate model. In the TOPSIS analysis, the following decision matrix was performed with " $\mathrm{m}$ " alternatives associated with " $\mathrm{n}$ " criteria, as shown in Figure S1b. The step-by-step exposition of the TOPSIS method for selecting the appropriate wastewater treatment alternative consists of six steps: (1) construct the normalized decision matrix; (2) construct the weighted normalized decision matrix; (3) determine the positive and negative ideal solutions; (4) calculate the measure of separation; (5) calculate the relative closeness to the ideal solution; and (6) rank the preference order.

Step 1: Construct the normalized decision matrix.

The first step was to construct the normalized decision matrix because the criteria information is available at different scales [10]. Hence, it was necessary to normalize the data before proceeding to 
the actual application of the TOPSIS method [30]. The vector normalization was determined as shown in Equation (3) as follows:

$$
r_{i j}=\frac{x_{i j}}{\sqrt{\sum_{i=1}^{m} X_{i j}^{2}}}
$$

where $r_{i j}$ is the vector normalization of the ith alternative with the $j$ th criteria, and $X_{i j}$ is the numerical outcome of the ith alternative with respect to the jth criteria.

Step 2: Construct the weighted normalized decision matrix.

The provision of the weight for each criterion is important for the application of a suitable weighting set for decision making. The weight-normalized decision matrix was calculated by Equation (4). In this research, six experiments were designed and carried out with different weights for each criterion to supplement the transparency for all criteria and alternatives and to reduce the subjectivity and uncertainty in the analysis, as shown in Table S5 in the Supplementary Material S1, as follows:

$$
\mathrm{V}_{\mathrm{ij}}=\mathrm{W}_{\mathrm{j}} \times \mathrm{r}_{\mathrm{ij}}
$$

such that $\mathrm{W}=\left(\mathrm{W}_{1}, \mathrm{~W}_{2}, \ldots, \mathrm{W}_{\mathrm{j}}, \ldots, \mathrm{W}_{\mathrm{n}}\right), \sum_{\mathrm{j}=1}^{\mathrm{n}} \mathrm{W}_{\mathrm{j}}=1$, where $\mathrm{W}_{\mathrm{j}}$ is the weight of the $\mathrm{jth}$ criteria and $\mathrm{V}_{\mathrm{ij}}$ is the weight-normalized decision matrix of the ith alternative with the jth criteria.

Step 3: Determine positive and negative ideal solution.

The positive and negative ideal solutions were determined by Equations (5) and (6) as follows:

$$
\begin{aligned}
& \text { PIS }=\left(V_{1}^{+}, V_{2}^{+}, \ldots, V_{j}^{+}, \ldots, V_{n}^{+}\right)=\left\{\left(\max _{i} V_{i j} \mid j \in J\right),\left(\min _{i} V_{i j} \mid j \in J^{\prime}\right) \mid i=1,2, \ldots, m\right\} \\
& \text { NIS }=\left(V_{1}^{-}, V_{2}^{-}, \ldots, V_{j}^{-}, \ldots, V_{n}^{-}\right)=\left\{\left(\min _{i} V_{i j} \mid j \in J\right),\left(\max _{i} V_{i j} \mid j \in J^{\prime}\right) \mid i=1,2, \ldots, m\right\}
\end{aligned}
$$

where PIS is the positive ideal solution, NIS is the negative ideal solution, $\mathrm{J}$ is a set of benefit criteria and $\mathrm{J}^{\prime}$ is a set of cost criteria. The ideal solution in terms of the environmental impact in this research can be obtained with a high value of the mean negative and a low value of the mean positive.

Step 4: Calculate the separation measure.

The calculations of the separation of each alternative from the positive and negative ideal solutions follow from Equations (7) and (8) as follows:

$$
\begin{aligned}
& \mathrm{S}_{\mathrm{i}}^{+}=\sqrt{\sum_{\mathrm{j}=1}^{\mathrm{n}}\left(\mathrm{V}_{\mathrm{ij}}-\mathrm{V}_{\mathrm{j}}^{+}\right)^{2}} \quad \mathrm{i}=1,2, \ldots, \mathrm{m} \\
& \mathrm{S}_{\mathrm{i}}^{-}=\sqrt{\sum_{\mathrm{j}=1}^{\mathrm{n}}\left(\mathrm{V}_{\mathrm{ij}}-\mathrm{V}_{\mathrm{j}}^{-}\right)^{2}} \quad \mathrm{i}=1,2, \ldots, \mathrm{m}
\end{aligned}
$$

where $S_{i}^{+}$is the distance of the positive ideal solution and $S_{i}^{-}$is the distance of the negative ideal solution.

Step 5: Calculate the relative closeness to the positive ideal solution.

The relative closeness of each alternative was defined as Equation (9) as follows:

$$
\mathrm{C}_{\mathrm{i}}^{+}=\frac{\mathrm{S}_{\mathrm{i}}^{-}}{\mathrm{S}_{\mathrm{i}}^{+}+\mathrm{S}_{\mathrm{i}}^{-}}
$$

where $\mathrm{C}_{i}^{+}$is the score of closeness to positive ideal solution with $0<\mathrm{C}_{i}^{+}<1$.

Step 6: Rank the preference order.

Choose an alternative with the maximum $\mathrm{C}_{\mathrm{i}}^{+}$in descending order for ranking. 


\subsection{Qualitative Estimation of the Environmental Criteria}

According to the several criteria of sustainability indicators, the environmental aspects have been focused on their suitability for wastewater treatment selection [21,31]. Therefore, the four criteria of land requirement, energy use in terms of electricity use, sludge production, and $\mathrm{CO}_{2}$ emission were considered to mainly investigate the environmental impacts of selected technologies in this study. Other criteria, such as social and economic criteria as in [32-34], were not considered due to data constraints.

The electricity demand was calculated from the oxygen requirement for the aeration process of 2 $\mathrm{kg} \mathrm{O} 2 / \mathrm{kWh}$ [35] and from the power requirement for sewage collection for only the centralized systems. The sludge production was considered from the amount of TSS remaining untreated by the WWTP by estimating approximately $50 \%$ of the TSS according to Wastewater Engineering [27]. In this research, $\mathrm{CO}_{2}$ emission was estimated from electricity use of approximately $672 \mathrm{~g} \mathrm{CO}_{2} / \mathrm{kWh}$ especially in Asia, but excluding China [36,37]. The estimation procedure and results of the four criteria are described in detail in the Supplementary Material S2.

\subsection{Analysis Procedure}

First, the raw wastewater parameters were obtained from the analytical results of the influent and effluent wastewater samples of a CBS model at Thongkhankham Village, Chanthabuly District. The second step was to estimate the daily wastewater flow by obtaining the population in the study area from the public water use from the census of the Vientiane Water Supply Enterprise [20]. The third step was the design step for each model by following the guidelines related to wastewater engineering. The fourth step was the BioWin simulation process to investigate the treatment efficiencies of the six models. In the final step, the TOPSIS analysis was applied to rank these alternatives to select the most appropriate wastewater treatment technology for the study area, as shown in Figure 3.

Since our study area was Vientiane, Laos, it was rather difficult to get enough necessary data for analysis and validation. Therefore, one of the purposes in conducting this study was to overcome such a difficulty and to have a reliable and scientifically correct result for assessing and selecting an appropriate technology for wastewater treatment. Therefore, we decided to use well-established tools and methodologies, such as BioWin and TOPSIS, rather than to try many variations in terms of methodology. Also, for assessing the values that appear in the Supplementary Material, we rather excessively use the relevant literature to overcome the lack of data.

\section{Results and Discussion}

\subsection{BioWin Simulation}

Figure 5 illustrates the simulated effluent BOD, COD, and TSS concentrations of the six wastewater treatment models. The constraints of the three wastewater effluent parameters in controlling the discharge of wastewater from households are BOD $<30 \mathrm{mg} / \mathrm{L}, \mathrm{COD}<125 \mathrm{mg} / \mathrm{L}$, and TSS $<40 \mathrm{mg} / \mathrm{L}$. Therefore, all the concentrations satisfy the water pollution control standards of Laos for household wastewater.

In terms of BOD concentration, On-site I shows the best performance among the models. Then, the CEWATS I depicts the second-highest performance in terms of effluent BOD concentration, followed by CEWATS II, DEWATS I, DEWATS II, and On-site II, in that order.

For the effluent COD concentration, CEWATS I shows the best performance with $76.8 \mathrm{mg} / \mathrm{L}$, followed by On-site I, CEWATS II, DEWATS I, On-site II, and DEWATS II.

With respect to TSS concentration, the CEWATS II exhibits the highest performance with $27.1 \mathrm{mg} / \mathrm{L}$, while On-site I indicates the lowest performance with $37.9 \mathrm{mg} / \mathrm{L}$. 


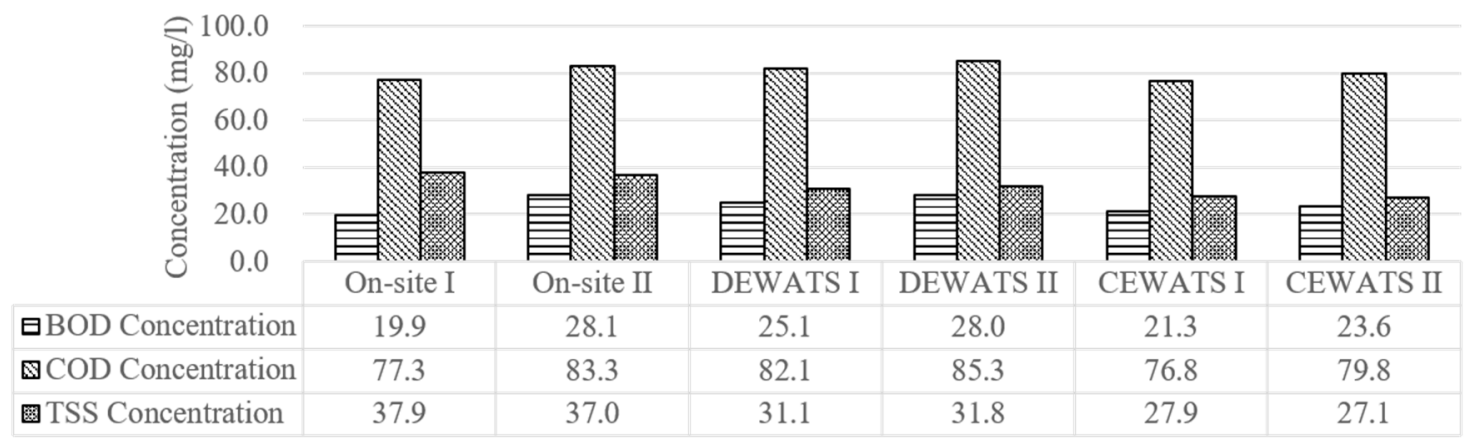

Figure 5. Simulated effluent concentrations of biochemical oxygen demand (BOD), chemical oxygen demand (COD), and total suspended solids (TSS) by BioWin for the six wastewater treatment models, satisfying the water pollution control standards of Laos.

\subsection{Environmental Impacts}

Table 3 illustrates the estimation results of the four criteria of land requirement, electricity use, sludge production, and $\mathrm{CO}_{2}$ emission based on engineering design and treatment aspects as shown in Table 2.

Table 3. Estimated results of the four criteria for the six wastewater treatment models.

\begin{tabular}{ccccc}
\hline \multirow{2}{*}{ Technologies } & \multicolumn{4}{c}{ Criteria } \\
\cline { 2 - 5 } & $\begin{array}{c}\text { Land } \\
\text { Requirement }\left(\mathbf{m}^{\mathbf{2}}\right)\end{array}$ & $\begin{array}{c}\text { Electricity Use } \\
\mathbf{( k W h / d})\end{array}$ & $\begin{array}{c}\text { Sludge Production } \\
\mathbf{( k g} / \mathbf{d})\end{array}$ & $\begin{array}{c}\mathbf{C O}_{\mathbf{2}} \text { Emission } \\
\mathbf{( k g} / \mathbf{d})\end{array}$ \\
\hline On-site I & 197,760 & 28,800 & 16,320 & 19,407 \\
On-site II & 150,720 & 63,360 & 16,320 & 42,578 \\
DEWATS I & 31,027 & 26,035 & 16,416 & 17,496 \\
DEWATS II & 36,230 & 53,530 & $16,473.6$ & 35,972 \\
CEWATS I & 32,013 & 20,788 & $16,660.8$ & 13,956 \\
CEWATS II & 21,981 & 65,693 & $13,359.63$ & 44,146 \\
\hline
\end{tabular}

In terms of the land requirement, On-site I and II require large areas because of the large number of required plants, while the CEWATS II requires the lowest land. For electricity use, the On-site II, DEWATS II, and CEWATS II demand high electrical power due to their aeration processes. In terms of sludge production, the CEWATS II shows the lowest value, whereas the other models show similar production.

With respect to $\mathrm{CO}_{2}$ emission, the On-site II, DEWATS II, and CEWATS II depict high emissions mainly due to the high electricity use for aeration. The CEWATS I presents the lowest emission, followed by DEWATS I and On-site I.

\subsection{Selection of the Optimized Wastewater Treatment Technology}

The six experiments were designed to investigate the different impacts of each criterion. The first experiment indicates the equal contribution of all criteria. The second and third experiments emphasize the impact of land requirement which is a critical factor in the densely-populated study area in Vientiane without much open space in the current conditions, while the fourth and fifth experiments mainly focus on the sludge production, which is indirectly related to the land requirement and management cost. The last sixth experiment was designed to investigate the greenhouse gas (GHG) emissions from each technology.

By applying the criteria weights in the TOPSIS analysis, as shown in Table S5 in the Supplementary Material S1, the results of six experiments in Table 4 demonstrate that the trickling filter model for CEWATS produced the highest scores of all the experiments. On the other hand, the on-site treatment 
system with an aeration process had the lowest score of all the experiments when compared with other treatment systems.

Table 4. The score and ranking of each alternative.

\begin{tabular}{|c|c|c|c|c|c|c|c|c|c|c|c|c|}
\hline \multirow{2}{*}{ Technologies } & \multicolumn{2}{|c|}{ 1st Experiment } & \multicolumn{2}{|c|}{ 2nd Experiment } & \multicolumn{2}{|c|}{ 3rd Experiment } & \multicolumn{2}{|c|}{ 4th Experiment } & \multicolumn{2}{|c|}{ 5th Experiment } & \multicolumn{2}{|c|}{ 6th Experiment } \\
\hline & Score & Rank & Score & Rank & Score & Rank & Score & Rank & Score & Rank & Score & Rank \\
\hline On-site I & 0.394 & 5 & 0.248 & 5 & 0.358 & 5 & 0.390 & 5 & 0.450 & 5 & 0.503 & 4 \\
\hline On-site II & 0.203 & 6 & 0.245 & 6 & 0.216 & 6 & 0.201 & 6 & 0.182 & 6 & 0.163 & 6 \\
\hline DEWATS I & 0.883 & 2 & 0.918 & 2 & 0.902 & 2 & 0.825 & 2 & 0.859 & 2 & 0.883 & 2 \\
\hline DEWATS II & 0.609 & 3 & 0.749 & 3 & 0.646 & 3 & 0.597 & 3 & 0.553 & 3 & 0.510 & 3 \\
\hline CEWATS I & 0.902 & 1 & 0.924 & 1 & 0.921 & 1 & 0.831 & 1 & 0.878 & 1 & 0.921 & 1 \\
\hline CEWATS II & 0.555 & 4 & 0.713 & 4 & 0.594 & 4 & 0.560 & 4 & 0.497 & 4 & 0.441 & 5 \\
\hline
\end{tabular}

Accordingly, the CEWATS I was ranked first in all experiments, followed by DEWATS I, DEWATS II, and CEWATS II. The models On-site I and II have the lowest ranks. Therefore, according to the results, it could be summarized that, based on land requirement, electricity use, sludge production, and $\mathrm{CO}_{2}$ emission criteria, the CEWATS system is more suitable for the study area than the on-site and decentralized treatment systems. Specifically, the trickling filter model in the centralized treatment system is the most appropriate technology of the six wastewater treatment systems considered in this study.

However, other affecting factors such as the economic cost of installation and maintenance, sludge management, sewage transportation to WWTP, discharge of the treated effluent, and social conditions were not taken into account in the criteria analysis due to lack of information. Moreover, in the TOPSIS analysis, the weights considered for criteria in the six experiments were rather arbitrarily determined, based on a number of test estimations. Therefore, the subjectivity and uncertainty issues still remain in the TOPSIS analysis for ranking the models.

\section{Conclusions}

This study assessed the six wastewater treatment systems based on two technologies, trickling filter and aeration/activated sludge, for Vientiane, Laos, in order to upgrade treatment efficiencies and protect the urban environment through the improvement of sanitation and wastewater treatment for a densely populated area. In the analysis, the main three steps consisted of the wastewater engineering calculation and design, the BioWin simulation to validate the calculation and design, and the TOPSIS analysis for ranking.

The results illustrated that the six wastewater treatment systems can remove BOD, COD, and TSS concentrations in wastewater effluents, achieving the Laos environmental control standards. These systems also vary in their efficiencies in terms of environmental impacts, such as land requirement, electricity use, sludge production, and $\mathrm{CO}_{2}$ emission.

Based on the analytical result, the trickling filter model in the centralized treatment system is the most appropriate technology among the six systems based on treating BOD, COD, and TSS under the four criteria. Moreover, the centralized wastewater treatment system is the optimized design for wastewater treatment in the growing city of Vientiane in term of environmental impacts.

The combined approach between BioWin and TOPSIS is useful for assessing sanitation and wastewater treatment development, as demonstrated in this study. BioWin can be used for validating all processes step-by-step until the final effluent satisfies the target standard of a study site. Then, the TOPSIS analysis helps the decision-making process by providing the ranks among alternatives. Therefore, applying BioWin and TOPSIS together is highly useful in the assessment of the optimized design of a wastewater treatment system.

However, it should be noted that the nitrogen concentration, which is a critical parameter to evaluate the performance in sewage treatment and is responsible for environmental issues such as eutrophication, was not taken into account in this study. Moreover, the technology considered for the 
on-site system in the study was chosen and assessed since the only pilot on-site system was based on the trickling filter system. In further work, it is recommended to assess other available technologies for the system.

To achieve sustainable development of sanitation and wastewater treatment management is a challenging target for developing countries. This research only provides fundamental analysis for wastewater treatment and alternative selections based on environmental protection conditions. The more varied technologies have to be considered and more criteria, such as sludge management, transportation of sewage to the WWTP, discharge of the treated effluent, and economic cost for installation, operation, and maintenance, also must be taken into account in the ranking process to address the subjectivity and uncertainty issues in the TOPSIS analysis in future works. Furthermore, in the combination of several opinions for technology selection, it is also of importance to provide logically and practically sound weights for criteria, specifically based on the opinions from experts, government, and local people in appropriate wastewater treatment selection.

Supplementary Materials: The following are available online at http://www.mdpi.com/2073-4441/11/5/1012/s1, Figure S1: (a) Euclidean distances (Si) of positive $(\mathrm{P})$ and negative $(\mathrm{N})$ ideal solution from alternatives (Ai), and (b) decision matrix of TOPSIS with " $\mathrm{m}$ " alternatives associated with " $\mathrm{n}$ " criteria, Table S1: Number of populations in Vientiane in 2015, Figure S2: Main pipeline system in the study area, Table S2: Analytical results of the wastewater in terms of BOD, COD and TSS concentration of the influent and effluent from a decentralized anaerobic wastewater treatment plant at Thongkhankham Village, Chanthabuly District, Table S3: The water use at the household level in Laos, Table S4: Population projections in 2025 and 2035 for the four study districts in Vientiane, Table S5: The considered weights for the four criteria for TOPSIS analysis, Table S6: Land requirement of each technology, Table S7: Electricity use of on-site systems and DEWATS, Table S8: Calculating dynamic head loss, Table S9: Calculating power requirement, Table S10: Electricity requirement for aeration, Table S11: Power for returning activated sludge, Table S12: Total electricity use for CEWATS II, Table S13: Sludge production, Table S14: Sludge production for CEWATS II, Table S15: Total sludge production, Table S16: $\mathrm{CO}_{2}$ emission.

Author Contributions: Conceptualization, C.K. and H.S.L.; methodology, C.K. and H.S.L.; software, C.K. and H.S.L.; validation, C.K. and H.S.L.; formal analysis, C.K. and H.S.L.; investigation, C.K. and H.S.L.; resources, C.K. and H.S.L.; data curation, C.K. and H.S.L.; writing-original draft preparation, C.K. and H.S.L.; writing-review and editing, C.K. and H.S.L.; visualization, C.K. and H.S.L.; supervision, H.S.L.; project administration, H.S.L.; funding acquisition, H.S.L.

Funding: This research is partly supported by the Grant-in-Aid for Scientific Research (17K06577) from JSPS, Japan.

Conflicts of Interest: The authors declare no conflict of interest.

\section{References}

1. WHO. Progress on Drinking Water, Sanitation and Hygiene; Update and SDG Baselines; World Health Organization (WHO) and the United Nations Children's Fund (UNICEF): Geneva, Switzerland, 2017; p. 66.

2. WEPA. Outlook on Water Environmental Management in Asia 2015; Institute for Global Environmental Strategies (IGES): Kanagawa, Japan, 2015; p. 129.

3. Tilley, E.; Ulrich, L.; Lüthi, C.; Reymond, P.; Zurbrügg, C. Compendium of Sanitation Systems and Technologies, 2nd Revised Ed.; Swiss Federal Institute of Aquatic Science and Technology (Eawag): Dübendorf, Switzerland, 2014; p. 175.

4. JICA. The Project for Urban Waster Environment Improvement in Ventiane Capital in Lao PDR; JICA: Tokyo, Japan, 2017; p. 186.

5. WREA. Agreement on National Environmental Standards; WREA: Vientiane, Laos, 2017.

6. UN. Transforming Our World: The 2030 Agenda for Sustainable Development; UN General Assembly: New York, NY, USA, 2015; p. 35.

7. UNICEF. Strategy for Water, Sanitation and Hygiene (2016-2030); UNICEF: New York, NY, USA, 2016; p. 60.

8. Ujang, Z.; Henze, M. Municipal Wastewater Management in Developing Countries; IWA Publishing: London, UK, 2006.

9. USEPA. Design Manual: Onsite Wastewater Treatment and Disposal Systems; US Environmental Protection Agency: Washington, DC, USA, 1980; p. 409. 
10. Kalbar, P.P.; Karmakar, S.; Asolekar, S.R. Selection of an appropriate wastewater treatment technology: A scenario-based multiple-attribute decision-making approach. J. Environ. Manag. 2012, 113, 158-169. [CrossRef] [PubMed]

11. Hwang, C.L.; Yoon, K. Multiple Attribute Decision Making: Methods and Applications A State-of-the-Art Survey; Springer: Berlin/Heidelberg, Germany, 1981.

12. Figueira, J.; Greco, S.; Ehrogott, M. Multiple Criteria Decision Analysis: State of the Art Surveys; Springer: New York, NY, USA, 2005; pp. 1-1045.

13. Tecle, A.; Fogel, M.; Duckstein, L. Multicriterion selection of wastewater management alternatives. J. Water Resour. Plan. Manag. 1988, 114, 383-398. [CrossRef]

14. Ellis, K.V.; Tang, S.L. Wastewater treatment optimization model for developing world. I: Model development. J. Environ. Eng. 1991, 117, 501-518. [CrossRef]

15. Tang, S.L.; Ellis, K.V. Wastewater treatment optimization model for developing world. II: Model testing. J. Environ. Eng. 1994, 120, 610-624. [CrossRef]

16. Zeng, G.; Jiang, R.; Huang, G.; Xu, M.; Li, J. Optimization of wastewater treatment alternative selection by hierarchy grey relational analysis. J. Environ. Manag. 2007, 82, 250-259. [CrossRef] [PubMed]

17. Cabrera, J.; Lee, H. Impacts of climate change on flood-prone areas in Davao oriental, Philippines. Water 2018, 10, 893. [CrossRef]

18. Bureau, L.S. Result of Population and Housing Census 2015; UNFPA: New York, NY, USA, 2016; p. 282.

19. Japan International Cooperation Agency (JICA). The Study on Improvement of Water Environment in Vientiane City; JICA: Tokyo, Japan, 2011; p. 93.

20. Ministry of Public Works and Transport (MPWT). The Water Supply Management and Technical Guideline; MPWT: Phnom Penh, Cambodia, 2014.

21. Balkema, A.J.; Preisig, H.A.; Otterpohl, R.; Lambert, F.J.D. Indicators for the sustainability assessment of wastewater treatment systems. Urban Water 2002, 4, 153-161. [CrossRef]

22. Tchobanoglous, G.; Burton, F.L.; Metcalf Eddy, Inc. Wastewater Engineering: Treatment, Disposal, and Reuse; McGraw-Hill: New York, NY, USA, 1991.

23. WHO. A Guide to the Development of On-Site Sanitation; WHO: Geneva, Switzerland, 1992; p. 229.

24. Ormiston, A.W.; Floyd, R.E. On-Site Wastewater Systems: Design and Management Manual; Auckland Regional Council: Auckland, New Zealand, 2004; Volume 58.

25. USEPA (US Environmental Protection Agency). Onsite Wastewater Treatment System Manual; US Environmental Protection Agency: Washington, DC, USA, 2002; p. 367.

26. Lin, S.D. Water and Wastewater Calculations Manual, 3rd ed.; McGraw-Hill Education: New York, NY, USA, 2014.

27. Tchobanoglous, G.; Burton, F.L.; Stensel, H.D.; Metcalf Eddy, Inc.; Burton, F. Wastewater Engineering: Treatment and Reuse; McGraw-Hill Education: New York, NY, USA, 2003.

28. Burton, F.L.; Tchobanoglous, G.; Tsuchihashi, R.; Stensel, H.D.; Metcalf Eddy, Inc. Wastewater Engineering: Treatment and Resource Recovery; McGraw-Hill Education: New York, NY, USA, 2013.

29. Environsim Associates. Process Model Formulation, 2017. Available online: https://envirosim.com/products/ biowin (accessed on 28 January 2018).

30. Kalbar, P.P.; Karmakar, S.; Asolekar, S.R. Life cycle-based decision support tool for selection of wastewater treatment alternatives. J. Clean. Prod. 2016, 117, 64-72. [CrossRef]

31. Lundin, M.; Molander, S.; Morrison, G.M. A set of indicators for the assessment of temporal variations in the sustainability of sanitary systems. Water Sci. Technol. 1999, 39, 235-242. [CrossRef]

32. Bradley, B.R.; Daigger, G.T.; Rubin, R.; Tchobanoglous, G. Evaluation of onsite wastewater treatment technologies using sustainable development criteria. Clean Technol. Environ. Policy 2002, 4, 87-99. [CrossRef]

33. Spuhler, D.; Scheidegger, A.; Maurer, M. Generation of sanitation system options for urban planning considering novel technologies. Water Res. 2018, 145, 259-278. [CrossRef] [PubMed]

34. Garrido-Baserba, M.; Hospido, A.; Reif, R.; Molinos-Senante, M.; Comas, J.; Poch, M. Including the environmental criteria when selecting a wastewater treatment plant. Environ. Model. Softw. 2014, 56, 74-82. [CrossRef]

35. Cakir, F.Y.; Stenstrom, M.K. Greenhouse gas production: A comparison between aerobic and anaerobic wastewater treatment technology. Water Res. 2005, 39, 4197-4203. [CrossRef] [PubMed] 
36. IPCC. Waste. In IPCC Guidelines for National Greenhouse Gas Inventories, Prepared by the National Greenhouse Gas Inventories Programe; IPCC: Geneva, Switzerland, 2006; Volume 5.

37. International Energy Agency (IEA). CO2 Emissions from Fuel Combustion 2017 Highlights; IEA: Paris, France, 2017; p. 162.

(C) 2019 by the authors. Licensee MDPI, Basel, Switzerland. This article is an open access article distributed under the terms and conditions of the Creative Commons Attribution (CC BY) license (http://creativecommons.org/licenses/by/4.0/). 